\title{
Pembuatan dan Pengujian Mesin Pemotong Lidi Tusuk Sate
}

\author{
Gusri Akhyar Ibrahim ${ }^{1}$, Arinal Hamni², Wahyu Budiono ${ }^{2}$ \\ 1, 2 Universitas Lampung
}

\begin{abstract}
Article History ABSTRACT
Received 28.08.2019

Received in revised form

25.11.2019

Accepted 04.12.2019

Available online 16.12.2019

MAKING AND TESTING OF SKEWERS CUTTING MACHINES. In Indonesia there are more than 100 types of bamboo that can be used by craftsmen, one of which is skewers. Skewers are promising commodities for business opportunities. The process of producing skewers are started from cutting down the bamboo, cutting bamboo, splitting bamboo, shriveling bamboo to become a stick skewer after that is done cutting the skewer sticks, drying sticks, polishing the sticks skewers and chopping sticks. The process of cutting a stick skewer which is done at this time is still using a simple tool, so the results are bad and the cutting time is very long. To maintain the quality of the results of a good stick skewer sticks and to increase the productivity of the stick skewers, the process of producing and testing of a skewer stick cutting machine is done. The method to produce a skewer stick cutting machine is done by designing the tool, determining the material to be used then making it. This skewer stick cutting machine is made with a press system and vertical cutting directions. From the results of testing the skewer stick cutting machine obtained that the quality of skewer cutting is good and the time required to cut is only 10 seconds. the difference is about 50 seconds faster than the hand saws used, so as to increase the productivity of the skewer sticks. The cutting machine was impelemented at home industry at Sidomulyo of South Lampung. Using the machine has increased productity and also quality of skewers.
\end{abstract}

KEYWORDS: Productivity, Quality, Skewers Cutting Machine.

DOI: $10.30653 / 002.201944 .207$

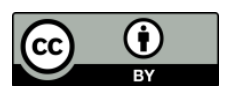

This is an open access article distributed under the terms of the Creative Commons Attribution 4.0 International License, which permits unrestricted use, distribution, and reproduction in any medium, provided the original work is properly cited. (c) 2019 Gusri Akhyar Ibrahim, Arinal Hamni , Wahyu Budiono.

\section{PENDAHULUAN}

Di Indonesia terdapat 100 lebih jenis bambu yang tersebar secara meluar di sebagaian besar wilayah, terutama daerah tropis. Tumbuhan ini digunakan untuk berbagai jenis kebutuhan dan produk secara konvensional (Batubara, 2002). Selain untuk kebutuhan bangunan rumah, bambu juga banyak digunakan untuk produk industri rumahan. Salah satu proudk industri rumah tangga yang dihasilakna dari tusuk sate dari bahan bambu. Tusuk sate merupakan komoditas yang menjanjikan untuk dijadikan

\footnotetext{
${ }^{1}$ Corresponding author: Program Studi Teknik Mesin Universitas Lampung. Jl. Prof. Sumantri Brojonegoro No. 1 Gedung Meneng, Banda Lampung 35145, Indonesia. Email: gusri.akhyar@eng.unila.ac.id
} 
peluang usaha (Widnyana, 2016). Proses pembuatan lidi tusuk sate diawali dengan penebangan bambu sebagai bahan utama pembuatan lidi tusuk sate, bambu yang telah ditebang, dipotong dengan ukuran $440 \mathrm{~mm}$, lalu bambu yang sudah dipotong dibelah dengan ketebalan $5 \mathrm{~mm}$ dan dilakukan proses penyerutan pada bambu yang sudah dibelah tadi dengan Ketebalan diameternya antara $2,5 \mathrm{~mm}$ s.d. $3 \mathrm{~mm}$, setelah proses penyerutan bambu sampai menjadi lidi bambu, proses selanjutnya yaitu pemotongan lidi tusuk sate dengan ukuran $220 \mathrm{~mm}$, kemudian proses penghalusan lidi bambu dan terakhir proses peruncingan lidi bambu, sehingga menjadi tusuk sate (Hamni, 2016).

Dari proses pembuatan tusuk sate di atas, pada proses pemotongan lidi tusuk sate masih menggunakan alat manual seperti pisau atau gergaji tangan, sehingga masih terdapat kendala, yaitu hasil pemotongan lidi tusuk sate masih banyak serabutnya pada permukaan hasil potongan, keseragaman hasil potongan tidak rata, patah pada bagian ujung lidi tusuk sate yang dipotong, dan waktu yang dibutuhkan untuk proses pemotongan terlalu lama.

Untuk mengatasi masalah yang terjadi di atas, penulis membuat dan menguji mesin pemotong lidi tusuk sate dengan tujuan untuk meningkatkan kualitas lidi tusuk sate dan meningkatkan produktivitas lidi tusuk sate. Kemudian mesin pemotong tusuk sate ini diimplementasikan pada kelompok pemuda (Karang Taruna) yang berlokasi di Kerajan, Desa Sidomulyo Lampung Selatan. Kelompok atau Karang Taruna Kerajan memproduksi tusuk sate dari bambu berkapasitas $1000 \mathrm{~kg}$ setiap bulannya.

\section{METODE PELAKSANAAN}

Pembuatan mesin pemotong lidi untuk tusuk sate dilakukan, terlebih dahulu dilakukan pembuatan gambar disain mesin pemotong. Hal ini bertujuan agar mesin yang dibuat mengunakan ukuran yang tepat dan mengurangi tingkat kesalahan pada proses pembuatannya. Mesin potong dirancang menggunakan motor listrik yang dihubungkan ke poros pisau potong menggunakan puli, dengan ukuran tertentu (Burhanuddin, 2012; Nurcahyo, 2017; Ibrahim, 2019). Adapun desain gambar dari mesin pemotong lidi tusuk sate seperti pada Gambar 1 .

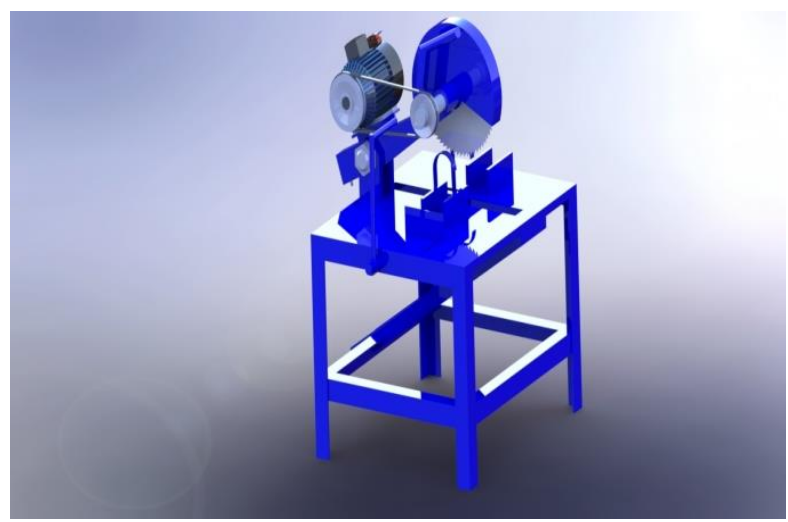

Gambar 1. Desain Gambar Mesin Pemotong Lidi Tusuk Sate

Alat dan bahan yang digunakan untuk pembuatan mesin pemotong lidi tusuk sate antaranya adalah mesin las, gerinda potong, mesin bor dan bebarapa peralatan pendukung lainnya. Mesin las digunakan untuk proses penyambungan rangka dudukan 
mesin potong, gerinda digunakan untuk memotong bahan besi dan membersihkan bagian sisa pengelasan, sedangkan mesin bor digunakan untuk pembuatan lobang. Adapun bahan-bahan yang digunakan untuk pembuatan mesin pemotong lidi tusuk sate dapat dilihat pada Tabel 1.

Tabel 1. Bahan-bahan yang digunakan

\begin{tabular}{lll}
\hline No. & Material & Kuantitas \\
\hline 1. & Motor listrik & 1 buah \\
2. & Besi siku & 3 batang \\
3. & Besi Plat & 1 lembar \\
4. & Bushing & 2 buah \\
5. & Poros & 1 buah \\
6. & V - belt & 1 buah \\
7. & Puli & 2 buah \\
8. & Bearing & 2 buah \\
9. & Mata pisau & 1 buah \\
10. & Tombol on/off & 1 buah \\
11. & Mur & 2 buah \\
12. & Cat & 1 kaleng \\
\hline
\end{tabular}

Prosedur pelaksanaan pembuatan mesin pemotong lidi tusuk sate ini dilakukan melalui beberapa langkah yaitu (1) perancangan alat, (2) pembuatan alat dan (3) pengujian alat. Perencanaan dilakukan menggunakan disain gambar yang dilengkapi dengan spesifikan, dimensi alat, termasuk dalam hal ini adalah kebutuhan bahan yang diperlukan. Pembuatan alat dilakukan di bengkel produksi menggunakan beberapa peralatan dengan sistem dan mekanisme yang sudah direncanakan. Sedangkan pengujian alat dilakukan untuk memastikan peralatan yang dibuat dapat berjalan dengan baik sesuai dengan kapasitas yang direncanakan (Andriyanto, 2016).

Implementasi mesin pemotong lidi tusuk sate adalah Karang Taruna Kerajan Desa Sidomulyo Lampung Selatan. Karang Taruna Kerajan memproduksi tusuk sate, dimana sebelum menggunakan mesin ini, pemotongan dilakukan secara manual, sehingga menghasilkan bekas potongan yang tidak rapi dan tidak seragam. Selain itu, pemotongan dilakukan dalam rentang waktu yang lama, sedangkan mesin ini mempercepat proses pemotongan dan menghasilkan bekas potongan yang lebih rapi dengan tidak berserabut.

Metode yang digunakan adalah pembuatan alat dan kemudian mengimplementasikan pada industri tusuk sate. Selanjutnya dengan menggunakan alat ini kapasitasitas produk bisa ditingkatkan, kualitas produk meningkat dan waktu yang digunakan untuk memperoduksi lebih singkat, sehingga dampak dari kegiatan ini dapat dirasakan oleh industri tusuk sate secara signifikan. 


\section{HASIL DAN PEMBAHASAN}

\section{Proses Pembuatan Mesin Pemotong Lidi Tusuk Sate}

Pada proses pembuatan mesin pemotong lidi tusuk sate dimulai dengan perancangan alat dengan membuat desain gambar dari alat tersebut. Tahapan ini bertujuan untuk mengetahui bentuk fisik hasilprancangan mesin pemotong lidi tusuk sate. Pembuatan desain gambar ini menggunakan aplikasi solid work. Selain untuk mengetahui bentuk dari rancangan alat, desain gambar ini juga digunakan sebagai gambar kerja pada pembuatan mesin pemotong lidi tusuk sate. Selanjutnya setelah desain gambar telah dibuat proses berikutnya yaitu menyiapkan alat dan bahan yang akan digunakan pada proses pembuatan mesin pemotong lidi tusuk sate, barulah setelah semua siap proses pembuatan dapat dilakukan. Tahapan-tahapan proses pembuatan mesin pemotong lidi tusuk sate ini adalah sebagai berikut:

\section{Pembuatan Meja}

Meja ini dibuat dengan ukuran panjang $78 \mathrm{~cm}$, lebar $60 \mathrm{~cm}$, dan tinggi $70 \mathrm{~cm}$, meja dibuat dengan ukuran tersebut karena disesuaikan dengan posisi kerja dan panjang benda kerja yang akan dipotong. Cara pembuatan meja yaitu menentukan bahan yang akan digunakan, pada pembuatan meja, bahan yang digunakan adalah besi siku lalu memotong besi siku 4 batang dengan ukuran $60 \mathrm{~cm}$ untuk pembuatan sisi lebar meja, 4 batang dengan ukuran $78 \mathrm{~cm}$ untuk membuat sisi panjang meja dan 4 batang dengan ukuran $70 \mathrm{~cm}$ untuk membuat kaki meja atau tinggi meja, Setelah memotong besi siku sesuai dengan ukuran yang diinginkan kemudian dilakukan pengelasan hingga terbentuk bentuk meja dan rapikan hasil pengelasan dengan gerinda penghalus. Gambar 2 berikut merupakan gambar kerja dari pembuatan meja.

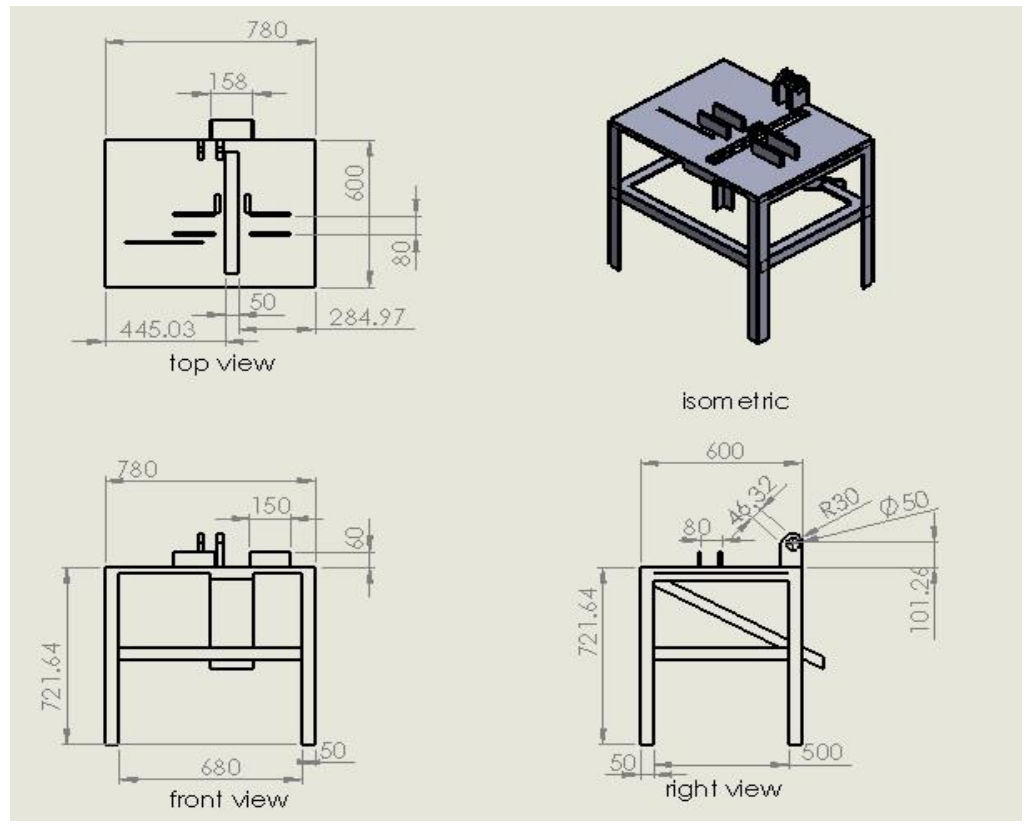

Gambar 2. Gambar Kerja Pembuatan Meja

\section{Pembuatan Tuas Jungkat-Jungkit}


Tuas jungkat-jungkit adalah komponen yang berfungsi untuk menggerakkan mata pisau naik turun pada saat proses pemotongan benda kerja, tuas jungkat-jungkit ini dibuat dengan ukuran panajang $57 \mathrm{~cm}$, pada tuas jungkat-jungkit juga terdapat bebarapa komponen yaitu motor, mata pisau, casing mata pisau, pulley, v- belt, dan tombol on/off (Daryanto, 1996).

Pembuatan tuas jungkat-jungkit dilakukan dengan cara sebagai berikut, yaitu Memotong pipa berdiameter $6 \mathrm{~cm}$ dengan panjang $45 \mathrm{~cm}$, lalu bagian depan pipa dibubut untuk dibuat ulir karena akan dipasang sambungan $\mathrm{T}$ untuk dudukan poros yang mengubungkan pulley dengan mata pisau, lalu memotong besi siku 2 batang dengan panjang $25 \mathrm{~cm}$, kemudian besi siku ini dilas di samping kanan dan kiri pipa bagian belakang sebagai dudukan motor, setelah itu memotong besi kotak dengan panjang $30 \mathrm{~cm}$ dan dilas di bagian depan pipa, sebagai tuas untuk gerakan jungkat-jungkit mata pisau pada saat memotong benda kerja dan juga di tuas ini dipasang tombol on/off untuk mengidupkan dan mematikan motor, kemudian Setelah dudukan jadi lalu pasang bushing di kanan dan kiri pipa tepat di bawah motor dengan cara dilas, dan juga lubangi pipa yang telah dipasang bushing hingga tembus sampai kanan dan kiri pipa, tujuan pipa yang telah dipasang bushing yaitu untuk memasang poros, bushing berfungsi sebagai pengganti bearing, jadi apabila dudukan dipasang pada meja poros diam dan dudukan dapat bergerak naik turun.

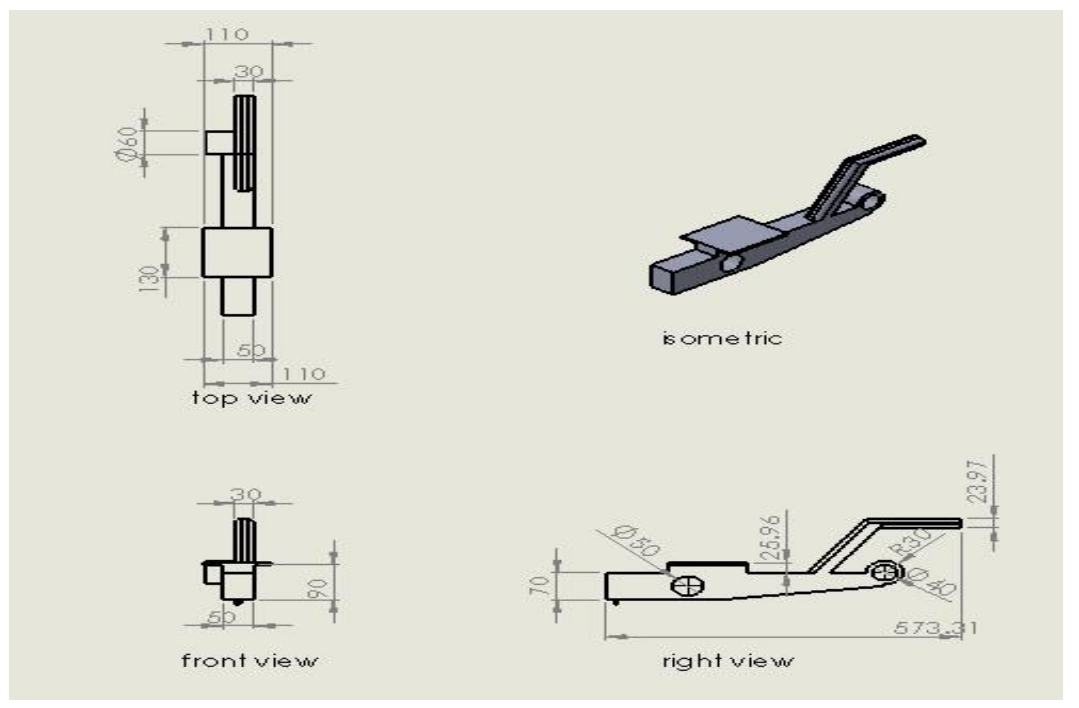

Gambar 3. Gambar Kerja Pembuatan Tuas Jungkat-jungkit

\section{Pembuatan Mal Ukur}

Mal ukur adalah komponen yang berfungsi sebagai alat bantu untuk menentukan ukuran benda kerja yang akan di potong, mal ukur ini dibuat dengan ukuran panjang 15 $\mathrm{cm}$, lebar $15 \mathrm{~cm}$ dan tinggi $6,5 \mathrm{~cm}$ dan mal ukur ini dibuat dapat digeser sesuai ukuran yang diinginkan tetapi mal ukur ini memiliki batas ukuran yaitu ukuran minimum $22 \mathrm{~cm}$ dan ukuran maksimum $44 \mathrm{~cm}$, batas ukuran ini di sesuaikan dengan batas potong benda kerja.

Pembuatan mal ukur dilakukan dengan cara sebagai berikut, pertama yang dilakukan untuk membuat mal ukur yaitu memetotong plat dengan tebal $3 \mathrm{~mm}$ dengan panjang $15 \mathrm{~cm}$ sebanyak 2 lembar (Wahyudi, 2011) Setelah itu lakukan pengelasan pada 
plat yang sudah dipotong diatas dengan bentuk seperti huruf L, kemudian beri lubang baut pada plat, kemudian setelah semua selesai dilakukan maka pasang mal ukur tersebut ke meja mesin potong, pada saat pemasangan mal ukur pada meja potong yang perlu diperhatikan yaitu kesesuaian penempatan angka ukuran pada meja potong dengan tanda panah yang terdapat pada mal ukur.

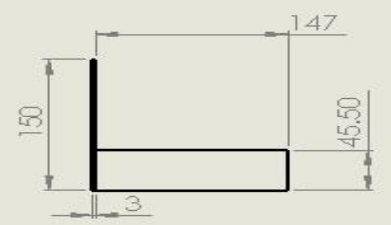

top view

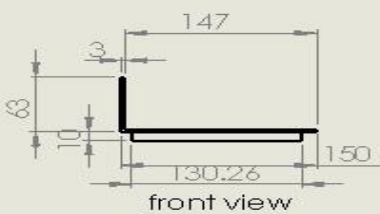

Gambar 4. Gambar Kerja Pembuatan Mal Ukur
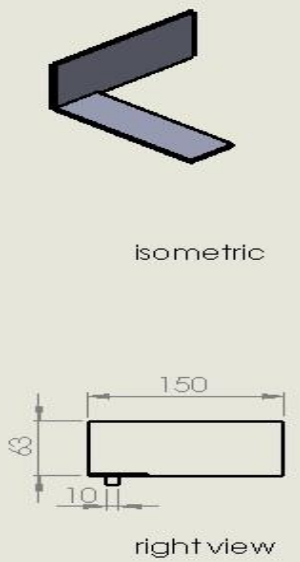

\section{Pembuatan Penutup Mata Pisau}

Penutup mata pisau adalah komponen yang berfungsi sebagai penutup mata pisau atau safety mesin pemotong lidi tusuk sate, untuk mengurangi resiko kecelakaan yang mungkin terjadi, penutup mata pisau ini dibuat dengan ukuran yang disesuaikan dengan diameter mata pisau. Pembuatan penutup mata pisau yaitu sebagai berikut, pertama memotong plat berbentuk lingkaran dengan diameter $32 \mathrm{~cm}$ kemudian potong plat tersebut hingga membentuk sudut $45^{\circ}$ setelah itu pada titik pusat lingkaran di lubangi dengan diameter $7 \mathrm{~cm}$, lalu memotong kembali plat berbentuk lingkaran dengan diameter $32 \mathrm{~cm}$ kemudian potong plat tersebut hingga membentuk sudut $45^{\circ}$ setelah itu pada titik pusat lingkaran di lubangi dengan diameter $4 \mathrm{~cm}$, setelah itu memotong plat dengan lebar $5 \mathrm{~cm}$ dan panjang $22 \mathrm{~cm}$ kemudian plat tersebut di benggkokan sesuai dengan 2 plat yang berbentuk lingkaran, kemudian setelah proses pemotongan plat selesai lalu kedua plat yang berbentuk lingkaran di atas dilas dengan plat dengan panjang $22 \mathrm{~cm}$ di atas, sehingga membentuk penutup untuk menutupi mata pisau. 


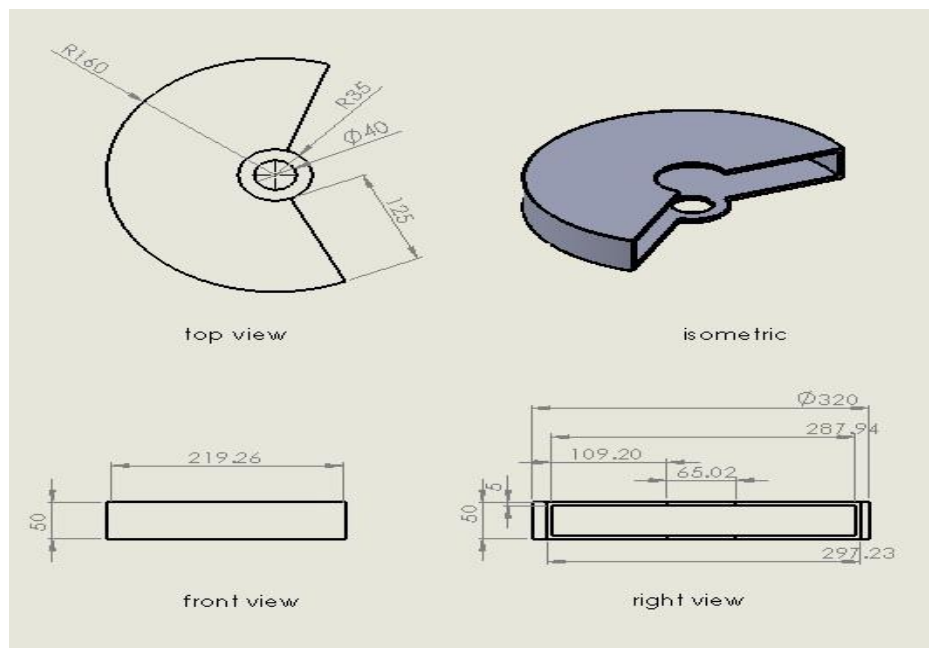

Gambar 5. Gambar Kerja Pembuatan Penutup Mata Pisau

\section{Pembuatan Tuas Pencekam}

Tuas pencekam adalah alat yang digunakan untuk mencekam benda kerja pada saat proses pemotongan, tujuan dibuatnya komponen ini untuk memudahkan operator pada saat melakukan proses pemotongan, dengan adanya komponen ini operator tidak perlu memegang benda kerja pada saat proses pemotongan, tuas pencekam ini dibuat dengan panjang $60 \mathrm{~cm}$ dan diameter cekam $10 \mathrm{~cm}$, jadi tuas pencekam ini hanya bias mencekam benda kerja yang mempunyai diameter $10 \mathrm{~cm}$. Pembuatan tuas pencekam yaitu sebagai berikut, hal pertama yang harus dilakukan dalam pembuatan tuas pencekam adalah memotong besi bulat berdiameter $2,5 \mathrm{~cm}$ dengan panjang $60 \mathrm{~cm}$, yang kedua yaitu memotong besi plat dengan ketebalan $3 \mathrm{~cm}$ dan panjangnya $15 \mathrm{~cm}$ kemudian dibengkokkan hingga membentuk cekaman, setelah semua selesai maka selanjutnya melakukan pengelasan terhadap besi bulat dan besi plat tersebut dan yang terakhir pasang tuas pencekam ini di bawah meja dengan posisi pencekam di atas meja dan tuasnya disebelah kanan meja.

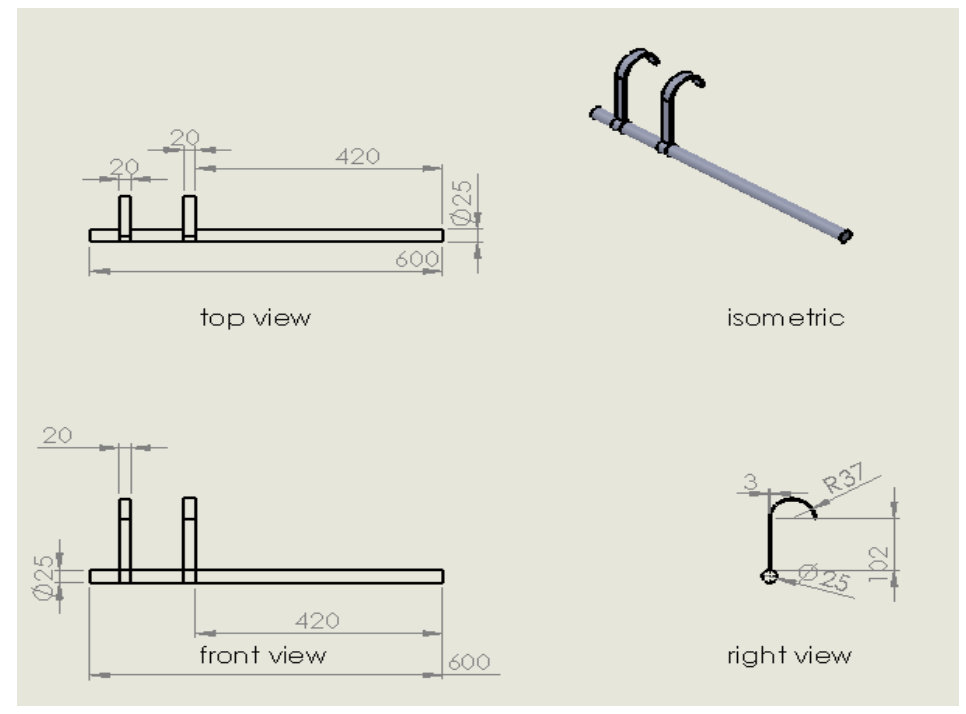

Gambar 6. Gambar Kerja Pembuatan Tuas Pencekam 


\section{Pengujian Mesin Pemotong Lidi Tusuk Sate}

Untuk mendapatkan hasil kerja mesin pemotong lidi tusuk sate ini perlu dilakukan pengujian. Pengujian ini bertujuan untuk mengetahui apakah alat ini berfungsi dengan baik saat digunakan untuk proses pemotongan. Pada proses pemotongan ini lidi tusuk sate akan diikat, dalam satu ikat berisi 500 lidi tusuk sate, kemudian dilakukan proses pemotongan. Proses pemotongan dilakukan dengan mesin pemotong lidi tusuk sate dan gergaji tangan untuk mengetahui kualitas lidi tusuk sate dan peningkatan produktivitas lidi tusuk sate.

Data hasil pengujian di atas dapat dilihat perbedaan hasil pemotongan lidi tusuk sate menggunakan mesin pemotong lidi tusuk sate dan hasil pemotongan lidi tusuk sate menggunakan gergaji tangan, bahwa hasil pemotongan menggunakan mesin pemotong lidi tusuk sate hasil pemotongannya bagus dan produktivitas lidi tusuk sate dapat meningkat dibandingkan memotong lidi tusuk sate menggunakan gergaji tangan.

Tabel 3. Data Hasil Pengujian

\begin{tabular}{llcl}
\hline Benda Uji & $\begin{array}{l}\text { Alat yang } \\
\text { Digunakan }\end{array}$ & $\begin{array}{l}\text { Waktu } \\
\text { Potong }\end{array}$ & Hasil Pengujian \\
\hline & Gergaji Tangan & 60 detik & $\begin{array}{l}\text { Terjadi patah pada bagian ujung } \\
\text { lidi tusuk sate yang telah di potong } \\
\text { Waktu pemotongan lama }\end{array}$ \\
\cline { 2 - 4 } $\begin{array}{l}\text { Lidi Tusuk } \\
\text { Sate }\end{array}$ & $\begin{array}{l}\text { Mesin Pemotong } \\
\text { Lidi Tusuk Sate }\end{array}$ & 10 detik & $\begin{array}{l}\text { Tidak patah pada bagian ujung lidi } \\
\text { tusuk sate yang dipotong } \\
\text { Waktu pemotongan lebih cepat dari } \\
\text { gergaji tangan, sehingga } \\
\text { produktivitas lidi tusuk sate } \\
\text { meningkat }\end{array}$ \\
\hline
\end{tabular}

Pada saat melakukan proses pemotongan menggunakan gergaji tangan posisi operator kurang nyaman pada saat melakukan pemotongan karena operator harus membungkuk. Lalu ketika melakukan pemotongan operator juga harus memutar benda kerja agar benda kerja dapat terpotong. Hal ini yang menyebabkan serabut banyak, ujung lidi tusuk sate hasil pemotongan ada yang patah, panjang hasil potongan tidak seragam dan waktu pemotongan lama. Waktu pemotongan yang dibutuhkan gergaji tangan untuk memotong lidi tusuk sate adalah 60 detik, jadi dalam satu jam gergaji tangan dapat memotong lidi tusuk sate sebanyak 60 ikat lidi tusuk sate, dalam satu ikat terdapat 500 lidi tusuk sate, sehingga gergaji tangan ini dalam satu jam hanya dapat memotong lidi tusuk sate sebanyak $60 \times 500=30000$ lidi tusuk sate.

Kemudian pada proses pemotongan menggunakan mesin pemotong lidi tusuk sate, posisi operator nyaman karena mesin pemotong lidi tusuk sate ini dibuat dengan tinggi $70 \mathrm{~cm}$, sehingga pada saat melakukan pemotongan operator tidak perlu membungkuk, lalu pada saat melakukan pemotongan lidi tusuk sate operator tidak perlu memutar benda kerja karena mesin A dapat langsung memotong satu ikat lidi tusuk sate. Oleh sebab itu memotong lidi tusuk sate menggunakan mesin pemotong lidi tusuk sate memperoleh hasi lebih bagus dan waktu yang dibutuhkan untuk memotong satu ikat lidi 
tusuk sate lebih cepat dari pada gergaji tangan, sehingga produktivitas lidi tusuk sate meningkat. Waktu yang dibutuhkan oleh mesin pemotong lidi tusuk sate untuk memotong satu ikat lidi tusuk sate adalah 10 detik, jadi dalam satu jam mesin pemotong lidi tusuk sate dapat memotong lidi tusuk sate sebanyak 360 ikat lidi tusuk sate, dalam satu ikat lidi tusuk sate memiliki jumlah 500 lidi tusuk sate jadi 360 × $500=180000$ lidi tusuk sate. Dan untuk resiko kecelakaan dalam melakukan pemotongan pada mesin pemotong lidi tusuk sate ini rendah karena mata pisau pada mesin pemotong lidi tusuk sate diberi penutup untuk mengurangi resiko terjadinya kecelakaan.

Penerapan teknologi mesin pemotongan lidi pada industri tusuk sate di Karang Taruna Kerajan telah mampu meningkatkan produktifitas dan kualitas hasil pemotongan. Dari segi produktifitas, untuk menghasilkan 500 tusuk sate hanya memerlukan waktu 10 detik, sedangkan bila menggunakan manual diperlukan waktu detik. Kemudian kualitas potong, bila menggunakan metode manual permukaan tidak rata, tidak sama panjang dan menyisakan serabut bambu, sedangkan bila menggunakan mesin pemotongan permukaan yang dihasilkan halus, pemotongan rata, tidak berserabut dan membutukan energy lebih sedikit.

Peningkatan kapasitas produksi tusuk sate meningkat setelah menggunakan mesin pemotongan lidi tusuk sate. Selain itu kualitas potongannya juga lebih baik, sehingga meningkatkan nilai tambah produk. Produksi pemotongan mampu mencapai 6x lipat lebih banyak dibandingkan dengan menggunakan manual, atau mampu mencapai $600 \%$. Dengan demikian, kapasitasitas produksi yang lebih besar dapat meningkatkan pemasaran, bahkan meluaskan pemasaran.

\section{SIMPULAN}

Berdasarkan hasil pembuatan dan pengujian dari mesin pemotong lidi tusuk sate dapat disimpulkan bahwa, dalam pembuatan alat pemotong bambu dan lidi tusuk sate ini melalui beberapa tahapan yaitu mendesain alat, persiapan alat dan bahan, pembuatan komponen alat, penyatuan semua komponen, dan uji fungsi alat. Dari hasil pengujian, melakukan pemotongan lidi tusuk sate dengan mesin pemotong lidi tusuk sate hasil potongannya tidak terjadi patah, sedangkan hasil pemotongan lidi tusuk sate menggunakan gergaji tangan hasil potongannya terjadi patah, sehingga kualitas potongan lidi tusuk sate menggunakan mesin mesin pemotong lidi tusuk sate lebih baik dari gergaji tangan. Dari hasil pengujian, mesin pemotong lidi tusuk sate dalam satu jam dapat memotong lidi tusuk sate sebanyak 180000 lidi tusuk sate sedangkan gergaji tangan hanya dapat memotong lidi tusuk sate sebanyak 30000 lidi tusuk sate, sehingga menggunakan mesin mesin pemotong lidi tusuk sate akan meningkatkan produktivitas lidi tusuk sate.

\section{REFERENSI}

Andriyanto, R. (2016). Pembuatan dan pengujian mesin penyerut tusuk sate mekanik. Laporan proyek akhir. Bandar Lampung: Universitas Lampung.

Batubara, R. (2002). Pemanfaatan bambu di Indonesia. Medan: Universitas Sumatera Utara Digital Library. 
Burhanuddin, Y. (2012). Dasar-dasar proses produksi untuk teknik mesin. Bandar Lampung: Universitas Lampung.

Daryanto (1996). Mesin perkakas bengkel. Jakarta: Rineka Cipta.

Hamni, A. (2016). Laporan KKN- PPM 2016. Bandar Lampung: Universitas Lampung.

Ibrahim, G. A. (2019). Pembuatan dan pengujian mesin penyerut tusuk sate mekanik. Sakai Sambayan Jurnal Pengabdian kepada Masyarakat, 3(1), 27-33.

Nurcahyo, Y. E. (2017). Penerapan enterprise resource planning (erp) adempiere modul manufacturing pada UMKM pembuatan mesin tusuk sate di Desa Terung Kulon Krian. TEKNOTERAP, 1(1), 26-37.

Wahyudi, C. (2011). Cara kerja mesin gergaji. Metro: Universitas Muhammadiyah Metro.

Widyana, K. (2016). Bambu dengan berbagai manfaatnya. Denpasar: Universitas Mahasaraswati. 